\title{
Nanoscale Silica Coated Graphene Oxide and Its Demulsifying Performance in Water-in-oil and Oil-in- water Emulsions
}

\section{Liwei Shen}

Yangtze University

Wenxiang Hu

Yangtze University

Zhiyun Lei

Petrochina Tarim Oilfield Co

Jianguo Peng

Petrochina Tarim Oilfield Co

\section{Enxiong Zhu}

Petrochina Tarim Oilfield Co

Xuanwei Zhang

Petrochina Tarim Oilfield Co

\section{Ming Yang}

Petrochina Tarim Oilfield Co

\section{Xuening Feng}

Yangtze University

\section{Ying Yang}

Yangtze University

Yuanzhu Mi (D michem@yangtzeu.edu.cn )

Yangtze University https://orcid.org/0000-0003-0944-4399

\section{Research Article}

Keywords: Nanocomposites, Oil-water emulsion, Demulsification, Mechanism

Posted Date: April 12th, 2021

DOI: https://doi.org/10.21203/rs.3.rs-363543/v1

License: (1) (1) This work is licensed under a Creative Commons Attribution 4.0 International License.

Read Full License 


\section{Abstract}

In present study, $\mathrm{GO} @ \mathrm{SiO}_{2}$ nanocomposites was prepared by coating nanoscale silica onto graphene oxide (GO). The nanocomposites were characterized with scanning electron microscopy (SEM), X-ray diffraction (XRD) and Fourier-transform infrared spectroscopy (IF-IR). Additionally, the demulsifying performance of the nanocomposites was investigated by the bottle test method. The results showed that $\mathrm{GO} @ \mathrm{SiO}_{2}$ nanocomposites had a good demulsifying performance both in oil-in-water $(\mathrm{O} / \mathrm{W})$ and water-inoil (W/O) emulsions. When the concentration of $\mathrm{GO} @ \mathrm{SiO}_{2}$ was 200 ppm in O/W emulsion, the optimal light transmittance of aqueous phase (LTA) and corresponding oil removal rate (ORR) at room temperature could reach $86.9 \%$ and $99.48 \%$, respectively. Also, GO@SiO ${ }_{2}$ had an excellent salt tolerance under acidic condition. Furthermore, $\mathrm{GO} @ \mathrm{SiO}_{2}$ nanocomposites also could demulsify the W/O emulsion, and the efficiency at $70^{\circ} \mathrm{C}$ could reach $80.5 \%$ when the concentration was $400 \mathrm{ppm}$.

\section{Introduction}

The development of oil extraction technologies usually accompanies with the formation water, which causes the ultimate production to exist in the form of an emulsion. In addition, the development of petroleum industry generates a large amount of oily wastewater(Fang et al. 2016, Peng et al. 2019, Sun et al. 2020, Teng et al. 2019). The oil-water emulsion can cause pipeline blockage, equipment corrosion, and serious water environmental pollution(Yuan et al. 2020, Zhang et al. 2013, Zhao et al. 2020). Therefore, the demulsification of oil-water emulsion is of great necessity.

Typically, oil-water emulsion is fairly stable. It is stabilized by natural surface active substances (asphaltenes, waxes, and resins) and inorganic solids through the vigorous $\pi-\pi$ interactions(Zhang et al. 2020b). Furthermore, steric effect and electrostatic force can also affect the stability of oil-water emulsion(Ma et al. 2020). In recent decades, chemical and physical methods are two main demulsifying approaches. Typical physical treatment techniques include centrifugation, electric field, membrane separation and microwave radiation(Chen et al. 2019a, Ghanbari \&Esmaeilzadeh 2018, Ichikawa et al. 2004, Tan et al. 2007, Xiong et al. 2018, Yi et al. 2019). However, they have many disadvantages such as high energy, low processing efficiency and complex equipment, etc. The chemical method is used to demulsify the emulsion by adding the demulsifier. It has the advantages of low energy consumption, fast processing speed and low cost. Therefore, it is widely adopted at present.

Chen et al.(Chen et al. 2019b) synthesized a magnetically responsive demulsifier called $\mathrm{Fe}_{3} \mathrm{O}_{4} @$ @yperbranched polyamidoamine-graphene oxide (MKh-GO), and ORR in emulsion reached 96.0\% when the dosage was $20 \mathrm{mg} / \mathrm{L}$ at $40{ }^{\circ} \mathrm{C}$. Furthermore, MKh-GO can be recycled seven times without obvious decrease in efficiency. Kuang et al.(Kuang et al. 2020) prepared a hyperbranched demulsifier (PTC) with trimethyl citrate as centronucleus. LTA could reach $91.5 \%$ with $50 \mathrm{mg} / \mathrm{L}$ of PTC at ambient temperature. 
The surface of carbon-based materials has a huge $\pi$ conjugate system. The oil-water interfacial film in crude oil emulsion is easily destroyed with the aid of $\pi-\pi$ or $p-\pi$ interactions between carbon-based materials and asphaltenes/resin(Cote et al. 2010). As a result, the droplets can gather at the interface and achieve the separation of oil and water(Liu et al. 2015a). Liu et al.(Liu et al. 2015a, Liu et al. 2015b, Wang et al. 2016) reported some carbon-based demulsifiers such as functionalized multiwalled carbon nanotubes, graphene oxide and reduced graphene oxide, which can initiate and achieve the oil-water separation in $\mathrm{O} / \mathrm{W}$ emulsion. Moreover, the carbon-based materials are environmentally friendly and easy to obtain. Recently, Chen et al.(Chen et al. 2015) used a two-step coating process to prepare a demulsifier. In their work, amorphous $\mathrm{SiO}_{2}$ coated $\mathrm{Fe}_{3} \mathrm{O}_{4}$ particles were further functionalized by $\mathrm{KH}-1231$. It showed a great demulsifying performance. Furthermore, the demulsifier can be recycled and reused. Wang et al. (Wang et al. 2011) prepared a demulsifier for the oil-in-water emulsion by grafting nano-SiO ${ }_{2}$ onto TA1031, and the efficiency could be improved by $20 \%$ and reached $97 \%$. In our previous work, some carbon-based materials such as $\mathrm{SiO}_{2} @ C S$, Ox-CB@SiO 2 and MCNT@ 3 -CD were used to demulsify the oilwater emulsions(Ye et al. 2019, Ye et al. 2020b, Yuan et al. 2020). Although all of them had an excellent demulsifying performance, there are still some disadvantages such as overdose, high operating temperature, or low applicability only applies to one type of emulsion ( $0 / \mathrm{W}$ or W/O emulsion).

For the purpose of improving the demulsifying performance and broadening the application scope, nano$\mathrm{SiO}_{2}$ coated graphene oxide $\left(\mathrm{GO} @ \mathrm{SiO}_{2}\right)$ was prepared by the sol-gel method in current work. The products are environmentally friendly, non-toxic and efficient. Especially, it can treat both W/O and O/W emulsions. It is expected to be applied to break the oil-water emulsion in petroleum and chemistry industry.

\section{Materials And Methods}

\subsection{Materials}

Sodium chloride $(\mathrm{NaCl})$ and flake graphite (700 meshes, $\geq 99.9 \%)$ were supplied by Shanghai Macklin biochemical Co. Ltd. Concentrated sulfuric acid $\left(\mathrm{H}_{2} \mathrm{SO}_{4}, \geq 95 \%\right)$, hydrochloric acid $(\mathrm{HCl}, 37 \%)$, potassium permanganate $\left(\mathrm{KMnO}_{4}, 99.5 \%\right)$, hydrogen peroxide aqueous solution $\left(\mathrm{H}_{2} \mathrm{O}_{2}, 35 \%\right)$ and sodium nitrate $\left(\mathrm{NaNO}_{3}, 99 \%\right)$ were purchased from Sinopharm Group Chemical Reagent Co. Ltd. Ethanol and tetraethyl orthosilicate (TEOS, 97\%) were purchased from Aladdin Chemistry (Shanghai, China). Crude oil was supplied by Fushan Oilfield (Hainan, China, density at $20^{\circ} \mathrm{C}: 0.8362 \mathrm{~g} / \mathrm{cm}^{3}$, viscosity at $25^{\circ} \mathrm{C}: 200.4$ $\mathrm{mPa} \cdot \mathrm{s}$, asphaltenes: $16.5 \%$, resin: $9.3 \%$, wax: $16.8 \%$, water: $1.56 \%)$. Diesel was provided by local gas station. All chemical reagents were analytical grade and directly used without further purification.

\subsection{Preparation of Graphene Oxide (GO)}

GO was prepared by a modified Hummers method(Venugopal et al. 2012). First, $2.5 \mathrm{~g}$ of $\mathrm{NaNO}_{3}$ and $2.0 \mathrm{~g}$ of graphite powder were dispersed into $180 \mathrm{ml} \mathrm{H}_{2} \mathrm{SO}_{4}$ stirred in an ice bath under ultra-sonication for 30 $\min$. Then, $15 \mathrm{~g}$ of $\mathrm{KMnO}_{4}$ was slowly added to the mixture. The mixture was constantly stirred for $24 \mathrm{~h}$ at room temperature. Next, $180 \mathrm{ml}$ of distilled water was poured into the mixture. The temperature was 
increased to $98{ }^{\circ} \mathrm{C}$ and hold for $1 \mathrm{~h}$. Afterward, $120 \mathrm{ml}$ of $\mathrm{H}_{2} \mathrm{O}_{2}(30 \mathrm{wt} \%)$ was added under stirring condition when the temperature of the mixture naturally deceased to $70{ }^{\circ} \mathrm{C}$. The mixture was continuously cooled to the ambient temperature and kept stirring for $1 \mathrm{~h}$. Finally, the as-prepared sample (GO) was washed with $5 \mathrm{wt} \% \mathrm{HCl}$ and distilled water several times and dried by vacuum freezing.

\subsection{Preparation of $\mathrm{GO} @ \mathrm{SiO}_{2}$}

$\mathrm{GO} @ \mathrm{SiO}_{2}$ was prepared by the sol-gel method. Briefly, $10 \mathrm{~g}$ of $\mathrm{GO}$ sol was dispersed into a mixed solution containing $30 \mathrm{ml}$ ethanol and $75 \mathrm{ml}$ distilled water under ultra-sonication and stirred for $30 \mathrm{~min}$. A few drops of $\mathrm{HCl}$ were then added into the mixture to adjust $\mathrm{pH}$ value to 5 . Next, $20 \mathrm{ml}$ absolute ethanol containing $5 \mathrm{~mL}$ TEOS were slowly dripped into the mixture and sonicated for $30 \mathrm{~min}$. Subsequently, the reaction mixture was transferred to a thermostat water bath and stirred for $10 \mathrm{~h}$ at $30^{\circ} \mathrm{C}$. Finally, the asprepared sample was washed with $\mathrm{NaOH}(4 \mathrm{wt} \%)$ and distilled water several times until pH value reached about 7 . The resulting product was dried by vacuum freezing and named as $\mathrm{GO}_{\mathrm{SSiO}} \mathrm{I}$. In addition, for the purpose of exploring the impact of $\mathrm{NaCl}$ on the demulsifying performance, some products were washed several times with a large amount of distilled water to remove $\mathrm{NaCl}$ and called as $\mathrm{GO}_{\mathrm{SiO}} \mathrm{II}$.

\subsection{Preparation of Oil-water Emulsion}

The oil-water emulsion was prepared by mixing crude oil and distilled water. Briefly, a certain amount of crude oil was directly added into the distilled water to prepare O/W emulsion ( $1 \mathrm{wt} \%$ crude oil) or W/O emulsion (22 wt\% crude oil). The mixtures were then stirred at $11000 \mathrm{rpm}$ for $30 \mathrm{~min}$ by using a homogenizer (FJ-200, Shanghai). The two emulsions kept stable for at least 24 hours at room temperature. The $\mathrm{pH}$ value of the emulsions was corrected by $\mathrm{HCl}$ or $\mathrm{NaOH}$ aqueous solution. Figure 2 is the micrographs of the oil-water emulsions observed under a polarizing microscope equipped with a digital camera (Caikang, DM2500P). It is obvious that Fig. 2a and Fig. 2b are typical O/W emulsion and W/O emulsion, respectively. The diameter of oil droplets and water droplets is about 1 to $5 \mu \mathrm{m}$ and 3 to 7 $\mu \mathrm{m}$, respectively.

\subsection{Demulsification Test}

The demulsifying experiments were carried out by bottle test. Typically, the suspensions containing different concentrations of $\mathrm{GO} @ \mathrm{SiO}_{2}$ were added into $20 \mathrm{ml}$ O/W emulsion at room temperature or $20 \mathrm{ml}$ of W/O emulsion at $70^{\circ} \mathrm{C}$. Subsequently, each bottle was violently shaken by hand for 2 min to assure that the demulsifier was entirely dispersed into the emulsions. Then, the $\mathrm{O} / \mathrm{W}$ emulsion was stood at ambient temperature and the $\mathrm{O} / \mathrm{W}$ emulsion was settled in water bath at $70{ }^{\circ} \mathrm{C}$ to explore the demulsification. The demulsifying performance of $\mathrm{O} / \mathrm{W}$ emulsion was estimated by LTA and ORR. The demulsifying efficiency ( $D E \%$ ) of $W / O$ emulsion was defined as $D E(\%)=V / V_{0} \times 100 \%$. Where $V_{0}$ is the water volume of initial emulsion, $\mathrm{V}$ is the volume of separated water.

\subsection{Characterization}


FT-IR with a resolution of $4 \mathrm{~cm}^{-1}$ (Nicolet 6700 , USA) was used to detect the groups on the samples. FESEM (MIRA3, TESCAN Co, Czech) was used to observe the morphology of the samples. The acceleration voltage of EDS was $15 \mathrm{kV}$. The X-ray diffraction spectrum was obtained with Cu radiation X-ray diffractometer (Bruker, Germany) within a $2 \theta$ range of $5^{\circ}-80^{\circ}$ at a rate of $0.05 / \mathrm{min}$. The dynamic interfacial tension (IFT, $\mathrm{mN} / \mathrm{m}$ ) and the wettability were measured with DSA 30 Process Tensiometer (Kruss. Germany) at $25^{\circ} \mathrm{C}$. The tensiometer was calibrated before each measurement. LTA was measured with a spectrophotometer.

\section{Results And Discussion}

\subsection{FT-IR spectra}

The FT-IR spectra of GO, $\mathrm{SiO}_{2}$ and $\mathrm{GO} @ \mathrm{SiO}_{2}$ are showed in Fig. 3. The peak at $3422 \mathrm{~cm}^{-1}$ is attributed to the stretching vibration of the $-\mathrm{OH}$ groups from $\mathrm{H}_{2} \mathrm{O}$ in air(Javadian \&Sadrpoor 2020). The peak at 3135 $\mathrm{cm}^{-1}$ is ascribed to the stretching vibration of $\mathrm{O}-\mathrm{H}$. The peaks at $2925 \mathrm{~cm}^{-1}$ and $2854 \mathrm{~cm}^{-1}$ are attributable to the $\mathrm{sp}^{2}$ and $\mathrm{sp}^{3} \mathrm{C}-\mathrm{H}$ stretching bond generated at the defect sites of the graphene network. The peak at $1731 \mathrm{~cm}^{-1}$ is assigned to the $\mathrm{C}=0$ stretching of the carboxyl groups on $\mathrm{GO}$ (Ye et al. 2020a). The peaks at $1625 \mathrm{~cm}^{-1}$ and $1629 \mathrm{~cm}^{-1}$ are ascribed to the stretching of the $\mathrm{C}=\mathrm{C}$ bond and $\mathrm{O}-\mathrm{H}$ groups attached to the $\mathrm{SiO}_{2}$ surface, respectively. The peak at $1400 \mathrm{~cm}^{-1}$ is attributed to the bending vibration of the $\mathrm{O}-\mathrm{H}$ bend. The absorption band of a symmetrical stretching vibration of Si-O-Si and Si-O-C are appeared at $1090 \mathrm{~cm}^{-1}$. The peaks at $790 \mathrm{~cm}^{-1}$ and $460 \mathrm{~cm}^{-1}$ are attributed to symmetric stretching vibration and bending vibration of $\mathrm{Si}-\mathrm{O}-\mathrm{Si}$, respectively. The peak of the wagging vibration of $\mathrm{Si}-\mathrm{OH}$ is at $950 \mathrm{~cm}^{-1}$. Therefore, it is believed that $\mathrm{SiO}_{2}$ is successfully coated onto $\mathrm{GO}$.

\subsection{FE-SEM observation}

The surface morphology of GO and GO@SiO2 was observed by FE-SEM and is shown in Fig. 4. As shown in Fig. 4a, the surface of GO is visibly curly and corrugated, it has the commonly ribbon structure of graphene oxide. In addition, it also can be found from Fig. 4b that a number of SiO2 microspheres are attached to the $\mathrm{GO}$ surface and the diameter of the microspheres is about $100 \mathrm{~nm}$. In order to further explore GO@SiO2, the elemental composition and distribution was observed by using an energy dispersive $\mathrm{X}$-ray spectrometer (EDS). EDS shows the peaks of $\mathrm{C}, \mathrm{O}$ and $\mathrm{Si}$, and no impurity elements is observed. Besides, the element scanning shows that $\mathrm{Si}$ (yellow) is evenly dispersed on the GO surface in Fig. 4c. The $\mathrm{C}$ element comes completely from GO, and the Si element come completely from SiO2. 0 element mainly comes from silicon dioxide, and some 0 element come from $\mathrm{GO}$. Moreover, it can be seen from Table 1 that the atom ratio of $\mathrm{C}$ and $\mathrm{Si}$ is about 5.45 by the EDS analysis. The result also indicates that $\mathrm{SiO} 2$ was coated onto $\mathrm{GO}$. 
Table 1

The atom ratio of $\mathrm{GO} @ \mathrm{SiO}_{2}$ from EDS

analysis.

\begin{tabular}{|llll|}
\hline Materials & $\mathbf{C}(\%)$ & $\mathbf{0}(\%)$ & Si (\%) \\
\hline${\mathrm{GO} @ \mathrm{SiO}_{2}}$ & 72.31 & 14.41 & 13.28 \\
\hline
\end{tabular}

\subsection{XRD patterns}

The XRD patterns of $\mathrm{GO}, \mathrm{SiO}_{2}$ and $\mathrm{GO} @ \mathrm{SiO}_{2}$ are displayed in Fig. 5. In XRD patterns, the crystal structure shows a strong narrow diffraction peak while the amorphous structure shows a wide diffraction peak. It shows that the peak at $10.29^{\circ}$ is corresponding to the (006) plane of graphite(Mousavi et al. 2020). The characteristic diffraction peaks of $\mathrm{GO}$ located at $26.6^{\circ}$ and $42.43^{\circ}$ are ascribed to (002) and (100) planes of graphite hexagonal lattices, respectively(Zhong et al. 2020). The reflection of (002) plane is very clear, it may be because the samples are abundantly ordered along the stacking direction and consist of graphene sheets(Gong et al. 2012). The reflection of (100) plane is related to the in-plane length of C-C in the network structure. The broad peak at $23.55^{\circ}$ is attributed to amorphous $\mathrm{SiO}_{2}$. As shown in Fig. $5 \mathrm{~b}$, the

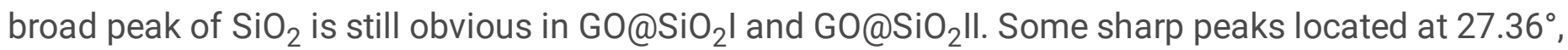
$31.7^{\circ}, 45.45^{\circ}, 53.85^{\circ}, 56.45^{\circ}, 66.20^{\circ}, 73.04^{\circ}$ and $75.26^{\circ}$ are corresponding to the (111), (200), (220), (311), (222), (400), (331) and (420) plane of $\mathrm{NaCl}$ (JCPDS: No.77-2064). $\mathrm{NaCl}$ comes from the addition of $\mathrm{HCl}$ and $\mathrm{NaOH}$ in the adjustment process of the $\mathrm{pH}$ value. Although the peak of $\mathrm{GO}$ is particularly low due to the influence of highly crystallized $\mathrm{NaCl}$, it can still be identified in $\mathrm{GO} @ S i O_{2}$. It also can be found that the characteristic diffraction peaks of $\mathrm{NaCl}$ in ${\mathrm{GO} @ S i \mathrm{~S}_{2}}_{2}$ ll disappeared. As mentioned above, it confirms that the targeted composite is $\mathrm{GO} @ \mathrm{SiO}_{2}$.

\subsection{Interfacial Activity of GO@SiO 2}

The interfacial activity is a significant factor affecting the migration of materials to the oil-water interface.(Kaushal et al. 2020, Zhang et al. 2020a) GO is amphiphilic which has the hydrophobic carbon substrate and the hydrophilic $-\mathrm{COOH}$ and $-\mathrm{OH}$ groups on its surface while $\mathrm{SiO}_{2}$ is completely hydrophilic. However, the hydrophilicity of $\mathrm{SiO}_{2}$ decreased due to the reaction of $\mathrm{GO}$ and $\mathrm{SiO}_{2}$ in the preparation process of $\mathrm{GO} @ \mathrm{SiO}_{2}$. Therefore,the as-prepared $\mathrm{GO} @ \mathrm{SiO}_{2}$ may be has a good interfacial activity. The interfacial activity of different samples was investigated in experimental bottles by observing their distribution in the oil-water interface. Each bottle contains $10 \mathrm{~mL}$ water and $10 \mathrm{~mL}$ diesel. The bottles were violently shaken by hand for 200 times and settled for 10 min and 3 days.

It can be seen from Fig. 6a that oil and water are insoluble, and the diesel-water interface is clear when the bottles were settled without shaking. A number of GO (Fig. 6a2) was dispersed to the bottom of the bottle and the water is brown, it may be due to its strong hydrophilic and some fine GO were evenly dispersed in water. Meanwhile, GO@SiO 2 (Fig. 6a3) stayed at the diesel-water interface and the water phase was very clear. It means that $\mathrm{GO}_{0} \mathrm{SiO}_{2}$ and $\mathrm{GO}$ have completely different hydrophilic properties. 
After shaken for 200 times and settled for 10 min and 3 days, it is found that the oil-water interface was still clear in blank sample. However, a very amount part of GO still stayed at the bottom of the bottle while most of them dispersed into the oil phase and became anomalous spherical bubbles (Fig. 6b2 and Fig. $6 c 2$ ). Moreover, these spherical bubbles remained unchanged for 3 days and the water phase always kept pale yellow. It is believed that GO formed the Pickering emulsion because it has colloidal particle characteristics(Cote et al. 2010, Lee et al. 2010). It also can be found that the volume of the diesel has increased slightly, it may be because the oil droplets were enveloped by membranous structure of GO. GO@SiO 2 (Fig. 6b3, Fig. 6c3) transferred promptly to the oil-water interface and stayed there. It shows that an emulsion layer appeared at the oil-water interface after standing for $10 \mathrm{~min}$, and its thickness is about $2 \mathrm{~mm}$. It is because that $\mathrm{GO} @ \mathrm{SiO}_{2}$ can act as an emulsifier due to its amphiphilic structure. After 3 days, the emulsion layer for $\mathrm{GO} @ \mathrm{SiO}_{2}$ was disappeared. However, $\mathrm{GO} @ \mathrm{SiO}_{2}$ still stayed at the oil-water interface without further sinking or diffusing into the water phase. It demonstrates that $\mathrm{GO}_{0} \mathrm{SiO}_{2}$ possess a high interfacial activity.

(a) Without shaking, (b) standing for 10 min after shaking, (c) standing for 3 days after shaking. Inset: Top view of the samples

\subsection{IFT of GO@SiO 2}

IFT can reflect the penetration of demulsifier molecules at the oil-water interface, which is a significant factor affecting the demulsifying performance. IFT of $\mathrm{GO}, \mathrm{SiO}_{2}$ and $\mathrm{GO} @ \mathrm{SiO}_{2}$ at the diesel-water emulsion are showed in Fig. 7a. The concentration of all samples is $200 \mathrm{mg} / \mathrm{L}$. It shows that the blank sample has a higher IFT (38.92 mN/M) than the other samples. It also can be noticed that the IFT of GO

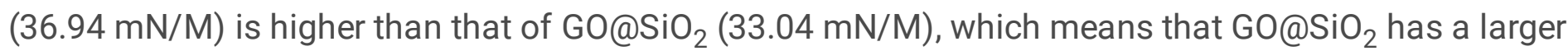
reduction of IFT than GO. Nevertheless, IFT of $\mathrm{SiO}_{2}$ is $25.64 \mathrm{mN} / \mathrm{M}$, which is lower than all other samples. It is reported that IFT is closely related to the demulsifying performance, and the lower IFT has better demulsifying performance(Razi et al. 2011). In our previous work, we found that IFT was not a decisive factor in demulsifying process. The demulsifying performance was affected by interfacial tension and interfacial activity, which are determined by the structure of the demulsifier(Ye et al. 2020a). Excellent performance of demulsifier needs not only high interfacial activity but also lower IFT. Higher interfacial activity can promote the rapid migration of demulsifier to the oil-water interface, while lower interfacial tension will endow the demulsifier a stronger ability to replace interfacial active substances(He et al. 2019).

Figure 7b shows IFT of GO@SiO ${ }_{2}$ with different dosages. IFT decreases from 36.21 mN/M to 33.04 $\mathrm{mN} / \mathrm{M}$ with the increase of dosage from $50 \mathrm{mg} / \mathrm{L}$ to $200 \mathrm{mg} / \mathrm{L}$. However, IFT increases from $33.04 \mathrm{mN} / \mathrm{L}$ to $34.24 \mathrm{mN} / \mathrm{M}$ when the dosage of $\mathrm{GO} @ S i O_{2}$ increases from $200 \mathrm{mg} / \mathrm{L}$ to $300 \mathrm{mg} / \mathrm{L}$. In other words, IFT reaches a lowest value when the dosage is $200 \mathrm{mg} / \mathrm{L}$. In demulsifying process, $\mathrm{GO} @ \mathrm{SiO}_{2}$ can quickly migrate to the interface and displace the intrinsic surfactants due to its high interfacial activity and low 
IFT. However, too much GO@SiO ${ }_{2}$ could form a stronger interface film and even initiate a new emulsification(Javadian \&Sadrpoor 2020).

\subsection{Wettability}

The wettability of demulsifiers is also an important factor which can affect the demulsifying performance. Three-phase contact angles $(\theta)$ can reflect the hydrophilicity and lipophilicity of the samples. The $\theta$ value of different samples were detected by a powder sheets method. As shown in Fig. 8 , the $\theta$ value of $G O$ is $83.62^{\circ} \pm 0.40^{\circ}$, which indicates that $\mathrm{GO}$ has slightly hydrophilic. It may be because there are hydrophilic groups such as $-\mathrm{COOH}$ and $-\mathrm{OH}$ groups on the $\mathrm{GO}$ surface(Kim et al. 2010). It also found that contact angle of $\mathrm{SiO}_{2}$ is $42.52^{\circ} \pm 0.11^{\circ}$. It demonstrates that $\mathrm{SiO}_{2}$ has strong hydrophilic due to a large number of hydrophilic groups on its surface. However, the $\theta$ value of $\mathrm{GO}_{S^{\prime}} \mathrm{SiO}_{2}$ is $88.75^{\circ} \pm$ $0.34^{\circ}$, which indicates that $\mathrm{GO} @ \mathrm{SiO}_{2}$ has an excellent amphiphilicity. It may be because the hydroxyl groups of $\mathrm{SiO}_{2}$ react with hydroxyl groups and carboxyl groups of $\mathrm{GO}$, which causes a part of the hydrophilic groups to disappear. When the $\theta$ value is close to $90^{\circ}$, it shows that the materials can stay at the oil-water interface well through the hydrophilic ends orientate to the water phase and the lipophilic ends orientate to the oil phase. In addition, it is reported that demulsifier has the optimal demulsifying effect when the $\theta$ value is between $85^{\circ}$ and $95^{\circ}$ (Lan et al. 2007, Ye et al. 2020a). Therefore, it is concluded that the $\theta$ value of $\mathrm{GO} @ \mathrm{SiO}_{2}$ is more beneficial to the demulsification.

\section{Demulsifying Performance}

\subsection{Demulsifying performance of different samples}

Demulsifying performance of the samples were evaluated by bottle test at ambient temperature and acidulous condition $(\mathrm{pH}=6)$. The dosage of the samples is $300 \mathrm{mg} / \mathrm{L}$. The LTA after standing for $30 \mathrm{~min}$ is displayed in Fig. 9. It is noticed that the blank is very stable and there is no obvious change. Although $\mathrm{GO}$ and $\mathrm{SiO}_{2}$ can initiate the oil-water separation, the water phases remain brown and light yellow, respectively. LTA of $\mathrm{GO}$ and $\mathrm{SiO}_{2}$ are $4 \%$ and $47.1 \%$ and the corresponding ORR are $96.1 \%$ and $97.9 \%$, respectively. However, $\mathrm{GO} @ \mathrm{SiO}_{2} \mathrm{I}$ and $\mathrm{GO} @ \mathrm{SiO}_{2} \mathrm{Il}$ exhibit an excellent demulsifying performance. LTA is $78.4 \%$ and $81.6 \%$, and the corresponding ORR are $99.14 \%$ and $99.27 \%$, respectively. It demonstrates that $\mathrm{SiO}_{2}$ modified GO greatly improves the demulsifying performance. Furthermore, GO@SiO2II has a higher LTA than GO@SiO ${ }_{2}$. Therefore, GO@SiO 2 ll was used to demulsify the O/W emulsion in the following experiments.

\subsection{Effect of $\mathrm{GO}_{\mathrm{SiO}}$ dosage on the demulsifying performance}


The demulsifier dosage significantly affects the demulsifying efficiency. In current experiments, the demulsifying performance of $\mathrm{GO} @ \mathrm{SiO}_{2}$ with the dosage from $0 \mathrm{mg} / \mathrm{L}$ to $300 \mathrm{mg} / \mathrm{L}$ is investigated at room temperature and acidulous condition $(\mathrm{pH}=6)$. The result is shown in Fig. 10 . It is obvious that the blank remains stable and has no obvious phase separation. LTA increases from 33-86.9\% with the increase of dosage from $50 \mathrm{mg} / \mathrm{L}$ to $200 \mathrm{mg} / \mathrm{L}$, which indicates the demulsifying performance increases with increasing dosage. However, LTA deceases with further increasing dosage. On the one hand, the demulsifiers cannot exert their action on the interface film after they have reached a saturation state. On the other hand, too much demulsifiers may lead to further emulsification of oil droplets due to its amphiphilic structure(Grenoble \&Trabelsi 2018). Therefore, the optimal dosage is $200 \mathrm{mg} / \mathrm{L}$, and the corresponding ORR can reach $99.48 \%$. It can be seen from Fig. 10 inset, although there is a small amount of $\mathrm{GO} @ \mathrm{SiO}_{2}$ attached to the bottle wall, the separated water is very clear.

\subsection{Effect of $\mathrm{pH}$ value on the demulsifying performance}

Effect of $\mathrm{pH}$ value on the demulsifying performance was also explored with $200 \mathrm{mg} / \mathrm{L}$ of $\mathrm{GO} @ S i O_{2}$ at ambient temperature. As shown in Fig. 11, there is no obvious oil-water separation in all samples under neutral and alkaline conditions. It may be based on the reason that the electrostatic repulsion between demulsifier and oil droplets is enhanced because the protons of the hydroxyl and carboxyl groups on $\mathrm{GO} @ \mathrm{SiO}_{2}$ are neutralized under the alkaline condition, which results in low demulsifying efficiency. However, the demulsifying efficiency increases with the decrease of $\mathrm{pH}$ value at acidic condition. LTA is $86.3 \%, 88.9 \%, 90.3 \%$ and the corresponding ORR are $99.45 \%, 99.56 \%, 99.61 \%$ when the pH value is 6,4 and 2, respectively. It is because hydroxyl groups and carboxyl groups on $\mathrm{GO} @ \mathrm{SiO}_{2}$ can exert their hydrophilia, which promotes the electrostatic attractive force between $\mathrm{GO}_{\mathrm{OSiO}}$ and oil droplets, and improve the demulsifying efficiency.

\subsection{Effect of salinity on the demulsifying performance}

The salinity has a significant influence on the properties of the emulsion. For the purpose of assessing the salinity effect on the demulsifying performance, a series of emulsions with various salinities (different $\mathrm{NaCl}$ concentrations) were prepared and $200 \mathrm{mg} / \mathrm{L}$ of $\mathrm{GO} @ \mathrm{SiO}_{2}$ was added to the emulsions. The results are shown in Fig. 12, the LTA slightly deceases from 86.6-78.8\% and ORR also deceases from $99.46-99.15 \%$ with the increase of salinity from $0 \mathrm{mg} / \mathrm{L}$ to $10000 \mathrm{mg} / \mathrm{L}$. It may be because an appropriate salinity changes the stability and viscosity of the emulsion by affecting the interfacial properties. However, the LTA and ORR are only reduction of $7.8 \%$ and $0.31 \%$, respectively. It indicates that $\mathrm{GO} @ \mathrm{SiO}_{2}$ has an excellent salt tolerance.

\subsection{The demulsifying performance of $\mathrm{GO} @ \mathrm{SiO}_{2}$ in W/O emulsion}


For the purpose of investigating the demulsifying performance of $\mathrm{GO} @ \mathrm{SiO}_{2}$ in W/O emulsion, $\mathrm{GO} @ \mathrm{SiO}_{2}$ with different dosages from $0 \mathrm{mg} / \mathrm{L}$ to $500 \mathrm{mg} / \mathrm{L}$ were added to the W/O emulsion at $70{ }^{\circ} \mathrm{C}$ for $180 \mathrm{~min}$.

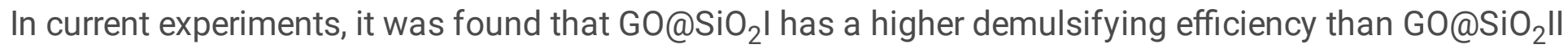
in W/O emulsion. Therefore, the $\mathrm{GO} @ \mathrm{SiO}_{2} \mathrm{I}$ was used to demulsify the W/O emulsion. As shown in Fig. 13, the blank control is fairly stable at a temperature of $70^{\circ} \mathrm{C}$. The demulsifying efficiency increases from $25.34-88.48 \%$ with increasing dosage from $100 \mathrm{mg} / \mathrm{L}$ to $700 \mathrm{mg} / \mathrm{L}$. Moreover, the demulsifying efficiency of $80.5 \%$ can be obtained when the dosage of $\mathrm{GO}_{\mathrm{SiO}_{2}}$ is $400 \mathrm{mg} / \mathrm{L}$. Although higher demulsifying efficiency may be obtained when more demulsifier was added, it indicates that the increase of the efficiency is not obvious. It also can be seen from Fig. 13 inset that the water phase is very limpid, and the oil-water interface is clear. As mentioned above, it believed that the demulsifier also has a good demulsifying performance in W/O emulsion.

\subsection{Possible Demulsifying Mechanism}

The possible demulsifying mechanism of $\mathrm{GO} @ S i O_{2}$ is described in Fig. 14. Typically, the stability of emulsion is mainly attributed to the protective film composed of asphaltene and resin at the oil-water interface. Therefore, the decisive factor for demulsifying is that the demulsifier can quickly move to the oil-water interface and destroy the interfacial film(Huang et al. 2020). As shown in Fig. 1, the matrix of $\mathrm{GO} @ \mathrm{SiO}_{2}$ is hydrophobic while its edge is modified by hydrophilic groups (such as $-\mathrm{COOH}$ and $\mathrm{SiO}_{2}$ ) to make it hydrophilic. Once it is added to the emulsion, $\mathrm{GO} @ \mathrm{SiO}_{2}$ can quickly migrate to the oil-water interface. As shown in Fig. 14e, the demulsifiers can be stabilized at oil-water interface by standing with

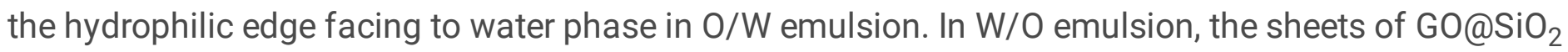
can be stabilized at the oil-water interface with more hydrophobic areas facing to oil phase (Fig. 14k)(Ma et al. 2016). When the demulsifier migrate to the oil-water interface, the demulsifier will destroy the protective film by strong adsorption with asphaltene and resin through $\pi-\pi$ or $n-\pi$ interactions(Liu et al. 2015b). Subsequently, small droplets can flocculate and coalescence to form the large droplets, and the oil and water can eventually be quickly separated under the gravity field(Teng et al. 2019).

\section{Conclusion}

In this work, a new and efficient $\mathrm{GO} @ \mathrm{SiO}_{2}$ demulsifier was prepared by coating $\mathrm{SiO}_{2}$ onto $\mathrm{GO}$ using a simple sol-gel method. The demulsifier can quickly demulsify $\mathrm{O} / \mathrm{W}$ and W/O emulsions. In O/W emulsion, LTA and ORR under optimal conditions could reach $86.9 \%$ and $99.48 \%$, respectively. Furthermore, it had a high salt tolerance. In W/O emulsion, $\mathrm{GO} @ \mathrm{SiO}_{2}$ had an efficiency of $80.5 \%$ when the dosage was 400 $\mathrm{mg} / \mathrm{L}$ at $70^{\circ} \mathrm{C}$. In addition, the possible demulsifying mechanism was also explored. The current work shows a good application prospect in petroleum and chemical industry.

\section{Declarations}




\section{Ethics approval and consent to participate}

Not applicable.

\section{Consent for publication}

Not applicable.

\section{Availability of data and materials}

All data generated or analysed during this study are included in this published article [and its supplementary information files].

\section{Competing interests}

The authors declare that they have no competing interests.

\section{Funding}

Not applicable.

\section{Authors' contributions}

SL: Conceptualization, Data curation, Investigation, Software, Validation, Visualization, Writing original draft, review and editing. HW: Investigation, Validation. LZ: Investigation, Resources. PJ: Investigation, Resources. ZE: Investigation, Resources. ZX: Investigation, Resources. YM: Investigation, Resources. FX: Validation. YY: Validation.MY: Conceptualization, Data curation, Formal analysis, Funding acquisition, Investigation, Methodology, Project administration, Resources, Supervision, Visualization, Writing review and editing.

\section{References}

1. Chen C, Weng D, Mahmood A, Chen S, Wang J (2019a) Separation Mechanism and Construction of Surfaces with Special Wettability for Oil/Water Separation. ACS Appl Mater Interfaces 11:1100611027

2. Chen $Y$, Lin $X$, Liu N, Cao Y, Lu F, Xu L, Feng L (2015) Magnetically recoverable efficient demulsifier for water-in-oil emulsions. Chemphyschem 16:595-600

3. Chen Y, Tian G, Liang H, Liang Y (2019b) Synthesis of magnetically responsive hyperbranched polyamidoamine based on the graphene oxide: Application as demulsifier for oil-in-water emulsions. Int J Energy Res 43:4756-4765

4. Cote LJ, Kim J, Tung VC, Luo J, Kim F, Huang J (2010) Graphene oxide as surfactant sheets. Pure Appl Chem 83:95-110 
5. Fang S, Chen T, Wang R, Xiong Y, Chen B, Duan M (2016) Assembly of Graphene Oxide at the Crude Oil/Water Interface: A New Approach to Efficient Demulsification. Energy Fuels 30:3355-3364

6. Ghanbari M, Esmaeilzadeh F (2018) Demulsification by increasing the gravitational force acting upon the dispersed phase owing to the adsorption/absorption of the magnetite particles. $\mathrm{J}$ Dispersion Sci Technol 40:1581-1590

7. Gong P, Wang Z, Wang J, Wang H, Li Z, Fan Z, Xu Y, Han X, Yang S (2012) One-pot sonochemical preparation of fluorographene and selective tuning of its fluorine coverage. J Mater Chem 22:1695016956

8. Grenoble Z, Trabelsi S (2018) Mechanisms, performance optimization and new developments in demulsification processes for oil and gas applications. Adv Colloid Interface Sci 260:32-45

9. He X, Liang C, Liu Q, Xu Z (2019) Magnetically responsive Janus nanoparticles synthesized using cellulosic materials for enhanced phase separation in oily wastewaters and water-in-crude oil emulsions. Chem Eng J 378:122045-122061

10. Huang Z, Luo X, Mi Y, Wu G, Wang C, Liu L, Ye F, Luo Y (2020) Magnetic recyclable carbon nanotubes and its demulsification performance in oily wastewater. Separation Science and Technology, 1-9

11. Ichikawa T, Itoh K, Yamamoto S, Sumita M (2004) Rapid demulsification of dense oil-in-water emulsion by low external electric field. Colloids Surf A 242:21-26

12. Javadian S, Sadrpoor SM (2020) Demulsification of water in oil emulsion by surface modified SiO2 nanoparticle. J Petrol Sci Eng 184:106547-106555

13. Kaushal S, Kaur N, Kaur M, Singh PP (2020) Dual-Responsive Pectin/Graphene Oxide (Pc/GO) nanocomposite as an efficient adsorbent for $\mathrm{Cr}$ (III) ions and photocatalyst for degradation of organic dyes in waste water. J Photochem Photobiol A 403:112841-112851

14. Kim J, Cote LJ, Kim F, Yuan W, Shull KR, Huang JX (2010) Graphene Oxide Sheets at Interfaces. J Am Chem Soc 132:8180-8186

15. Kuang J, Mi Y, Zhang Z, Ye F, Yuan H, Liu W, Jiang X, Luo Y (2020) A hyperbranched Poly(amido amine) demulsifier with trimethyl citrate as initial cores and its demulsification performance at ambient temperature. Journal of Water Process Engineering 38:101542-101550

16. Lan Q, Liu C, Yang F, Liu S, Xu J, Sun D (2007) Synthesis of bilayer oleic acid-coated Fe304 nanoparticles and their application in pH-responsive Pickering emulsions. J Colloid Interface Sci 310:260-269

17. Lee DW, De Los Santos VL, Seo JW, Leon Felix L, Bustamante DA, Cole JM, Barnes CH (2010) The structure of graphite oxide: investigation of its surface chemical groups. J Phys Chem B 114:57235728

18. Liu J, Li X, Jia W, Ding M, Zhang Y, Ren S (2015a) Separation of Emulsified Oil from Oily Wastewater by Functionalized Multiwalled Carbon Nanotubes. J Dispersion Sci Technol 37:1294-1302

19. Liu J, Li X, Jia W, Li Z, Zhao Y, Ren S (2015b) Demulsification of Crude Oil-in-Water Emulsions Driven by Graphene Oxide Nanosheets. Energy Fuels 29:4644-4653 
20. Ma J, Li X, Zhang X, Sui H, He L, Wang S (2020) A novel oxygen-containing demulsifier for efficient breaking of water-in-oil emulsions. Chem Eng J 385:123826-123836

21. Ma S, Wang Y, Wang X, Li Q, Tong S, Han X (2016) Bifunctional Demulsifier of ODTS Modified Magnetite/Reduced Graphene Oxide Nanocomposites for Oil-water Separation. ChemistrySelect 1:4742-4746

22. Mousavi SR, Asghari M, Mahmoodi NM (2020) Chitosan-wrapped multiwalled carbon nanotube as filler within PEBA thin film nanocomposite (TFN) membrane to improve dye removal. Carbohydr Polym 237:116128-116138

23. Peng M, Zhu Y, Li H, He K, Zeng G, Chen A, Huang Z, Huang T, Yuan L, Chen G (2019) Synthesis and application of modified commercial sponges for oil-water separation. Chem Eng J 373:213-226

24. Razi M, Rahimpour MR, Jahanmiri A, Azad F (2011) Effect of a Different Formulation of Demulsifiers on the Efficiency of Chemical Demulsification of Heavy Crude Oil. Journal of Chemical Engineering Data 56:2936-2945

25. Sun H, Wang Q, Li X, He X (2020) Novel polyether-polyquaternium copolymer as an effective reverse demulsifier for O/W emulsions: Demulsification performance and mechanism. Fuel 263:116770116776

26. Tan W, Yang XG, Tan XF (2007) Study on Demulsification of Crude Oil Emulsions by Microwave Chemical Method. Sep Sci Technol 42:1367-1377

27. Teng H, Chen C, Yan S, Ye D, Zhang L (2019) Modified Hyperbranched Polyethylenimine as a Novel Demulsifier for Oil-in-Water Emulsions. Energy Fuels 33:10108-10114

28. Venugopal G, Krishnamoorthy K, Mohan R, Kim S-J (2012) An investigation of the electrical transport properties of graphene-oxide thin films. Mater Chem Phys 132:29-33

29. Wang FH, Shen LB, Zhu H, Han KF (2011) The Preparation of a Polyether Demulsifier Modified by Nano-SiO2and the Effect on Asphaltenes and Resins. Pet Sci Technol 29:2521-2529

30. Wang H, Liu J, Xu H, Ma Z, Jia W, Ren S (2016) Demulsification of heavy oil-in-water emulsions by reduced graphene oxide nanosheets. RSC Advances 6:106297-106307

31. Xiong Y, Huang X, Liu J, Lu L, Peng K (2018) Preparation of magnetically responsive bacterial demulsifier with special surface properties for efficient demulsification of water/oil emulsion. Renewable Energy 129:786-793

32. Ye F, Jiang X, Mi Y, Kuang J, Huang Z, Yu F, Zhang Z, Yuan H (2019) Preparation of oxidized carbon black grafted with nanoscale silica and its demulsification performance in water-in-oil emulsion. Colloids Surf A 582:123878-123886

33. Ye F, Wang Z, Mi Y, Kuang J, Jiang X, Huang Z, Luo Y, Shen L, Yuan H, Zhang Z (2020a) Preparation of reduced graphene oxide/titanium dioxide composite materials and its application in the treatment of oily wastewater. Colloids Surf A 586:124251-124261

34. Ye F, Zhang Z, Mi Y, Huang Z, Yuan H, Zhang Z, Luo Y (2020b) Carbon nanotubes grafted with $\beta$ cyclodextrin by an ultrasonication method and its demulsification performance in oily wastewater. Colloids Surf A 600:124939-124949 
35. Yi G, Fan X, Quan X, Chen S, Yu H (2019) Comparison of CNT-PVA membrane and commercial polymeric membranes in treatment of emulsified oily wastewater. Frontiers of Environmental Science Engineering 13:23-31

36. Yuan H, Zhang Z, Mi Y, Ye F, Liu W, Kuan J, Jiang X, Luo Y (2020) Demulsification of WaterContaining Crude Oil Driven by Environmentally Friendly SiO2@CS Composite Materials. Energy Fuels 34:8316-8324

37. Zhang C, Gao J, Hankett J, Varanasi P, Borst J, Shirazi Y, Zhao S, Chen Z (2020a) Corn Oil-Water Separation: Interactions of Proteins and Surfactants at Corn Oil/Water Interfaces. Langmuir 36:4044-4054

38. Zhang X, Chen S, Han Q, Ding M (2013) Preparation and retention mechanism study of graphene and graphene oxide bonded silica microspheres as stationary phases for high performance liquid chromatography. J Chromatogr A 1307:135-143

39. Zhang Z, Shen L, Hu W, Mi Y, Yuan H, Kuang J, Ye F, Jiang X, Luo Y, Liu W, Xie F (2020b) Treatment of Oily Wastewater Using a Hyperbranched Poly (amido amine) Demulsifier with 1,4-Phenylene Diamine as Central Core. ChemistrySelect 5, 9980-9988

40. Zhao B, Ren L, Du Y, Wang J (2020) Eco-friendly separation layers based on waste peanut shell for gravity-driven water-in-oil emulsion separation. J Clean Prod 255:120184-120194

41. Zhong Y, Li Q, Liu R (2020) Blueberry-Peel-Derived Porous Carbon for High-Performance Supercapacitors: The Effect of N-Doping and Activation. ChemistrySelect 5, 1029-1036

\section{Figures}

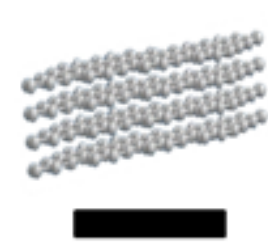

Graphite
Oxidation

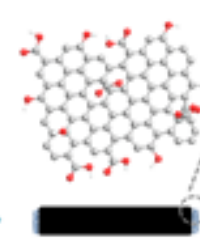

GO

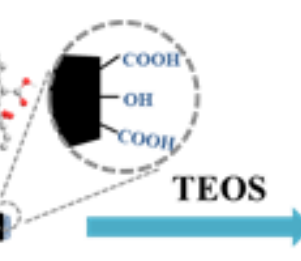

Sol-gel method

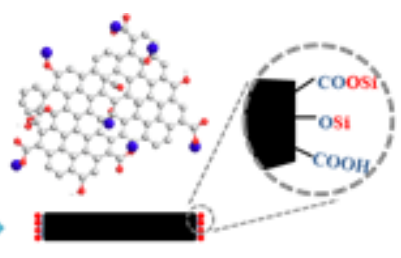

GO@ $\mathrm{SiO}_{2}$

\section{Figure 1}

Synthesis schematic of GO@SiO2. 


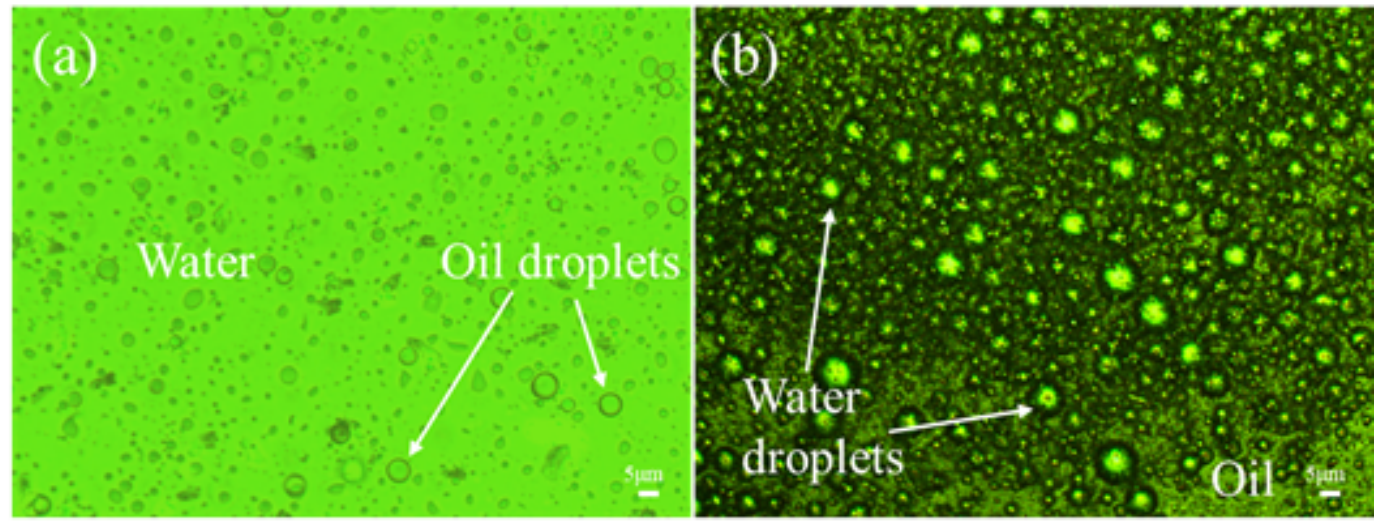

Figure 2

Optical images of O/W emulsion (a) and W/O emulsion (b).

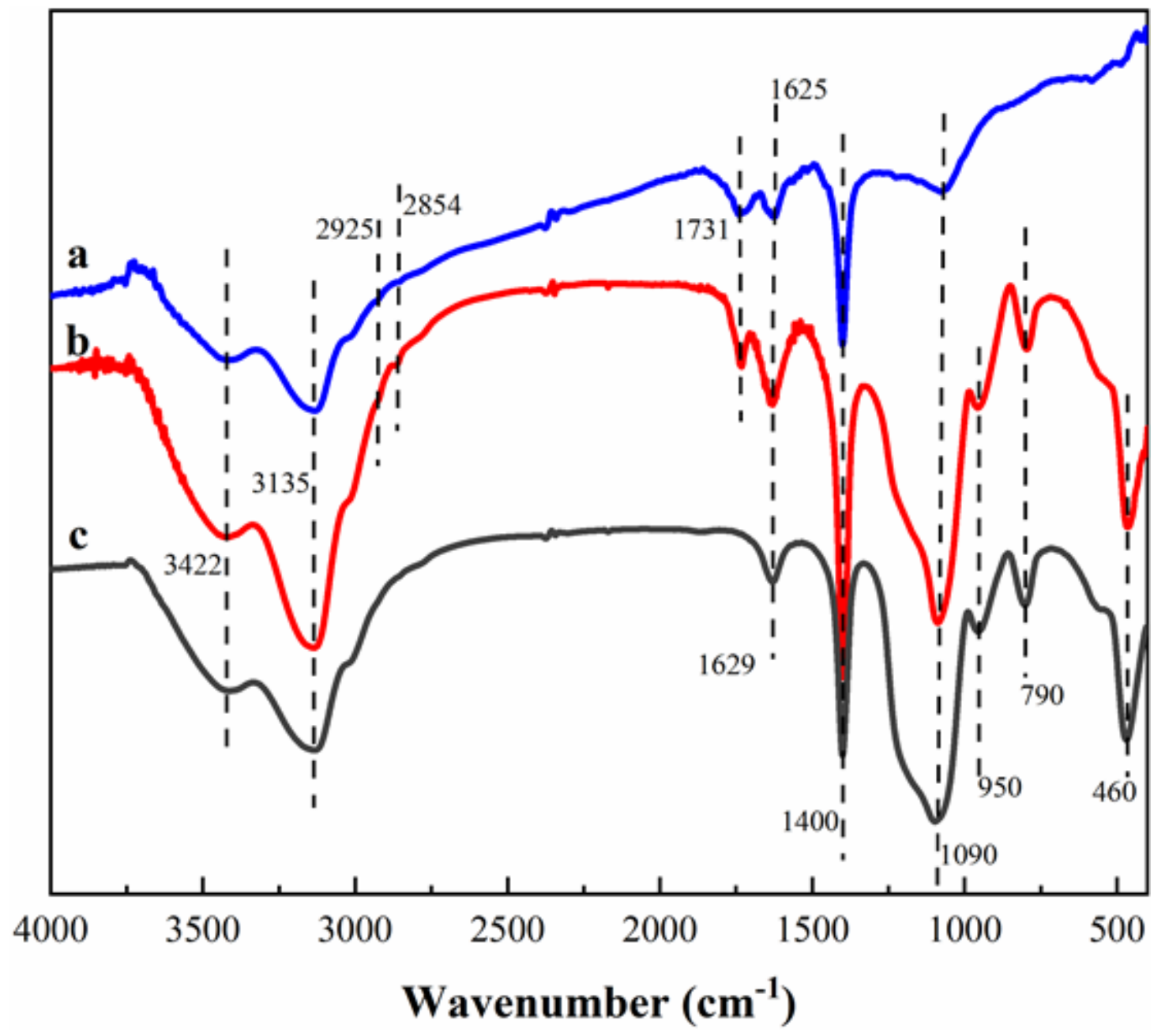

Figure 3

FT-IR spectra of GO(a), GO@SiO2(b) and SiO2(c). 


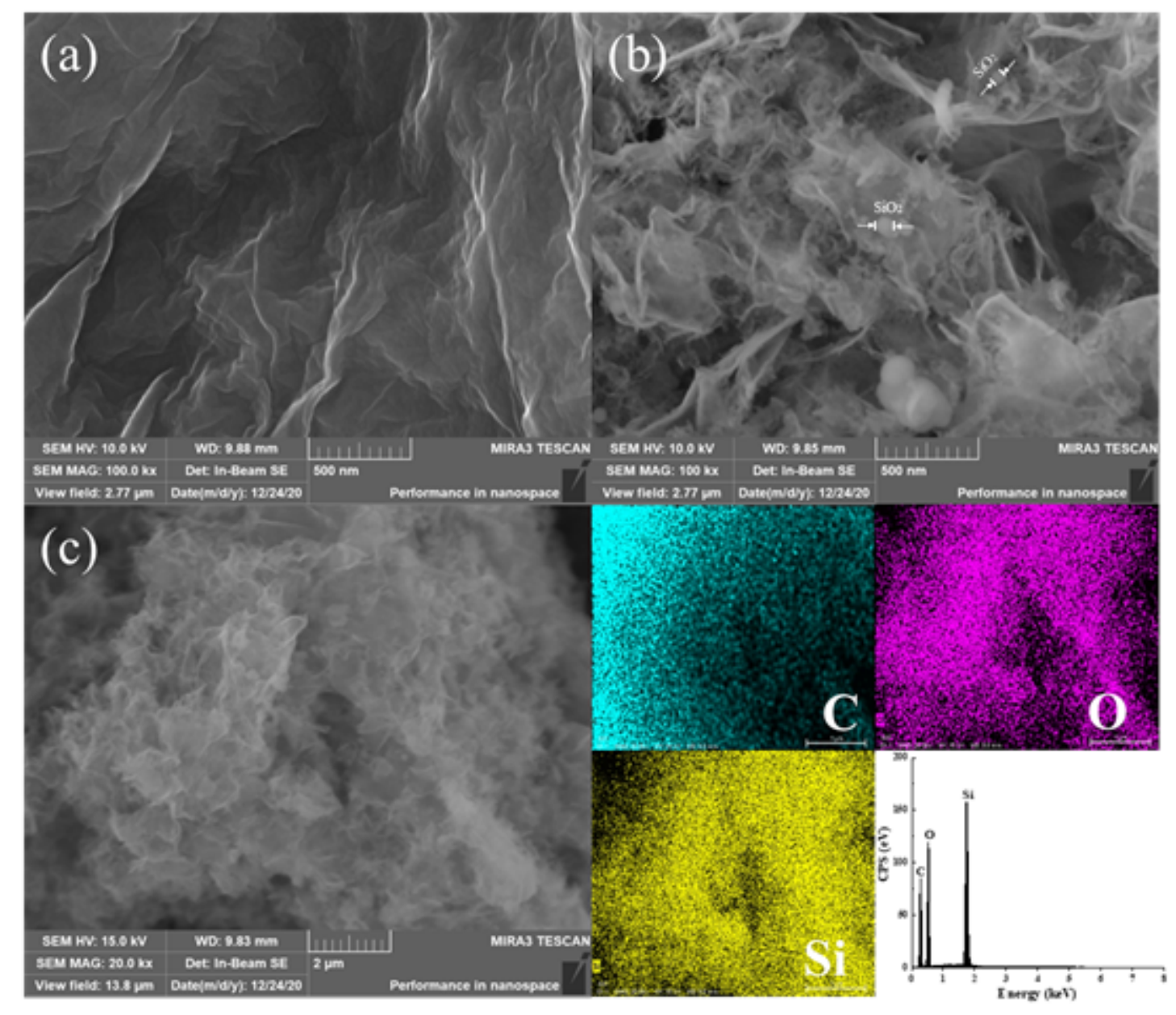

Figure 4

SEM images of GO(a), GO@SiO2 (b) and EDS mapping images (c) of C (blue), 0 (purple), Si (yellow) from GO@SiO2. Inset: the EDS spectrum of GO@SiO2.
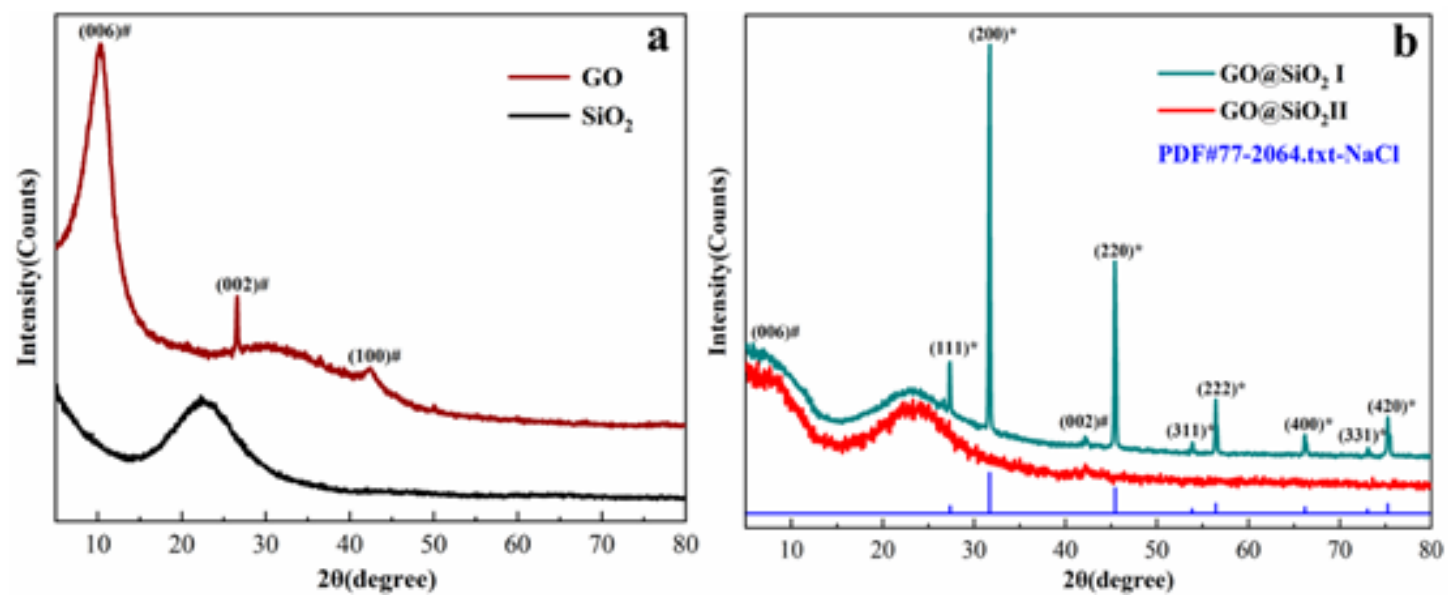

Figure 5

XRD patterns of GO, SiO2, GO@SiO2 I and GO@SiO2 II 

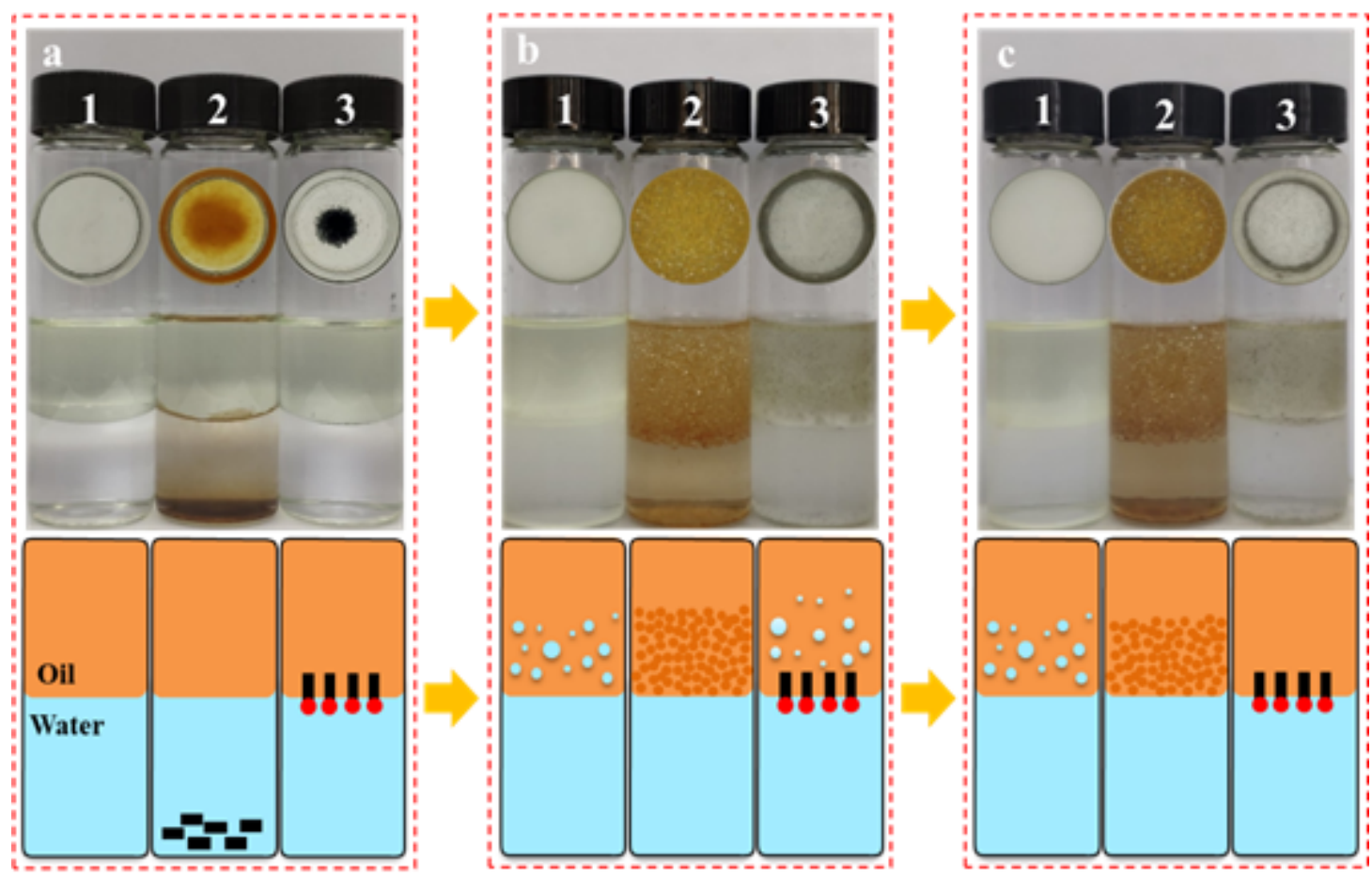

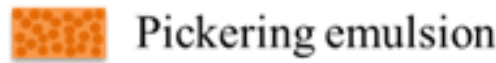
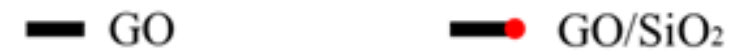

\section{Figure 6}

Interfacial activity of blank (1), GO (2) and GO@SiO2 (3) in diesel-water mixture and their corresponding schematic diagram. (a) Without shaking, (b) standing for 10 min after shaking, (c) standing for 3 days after shaking. Inset: Top view of the samples
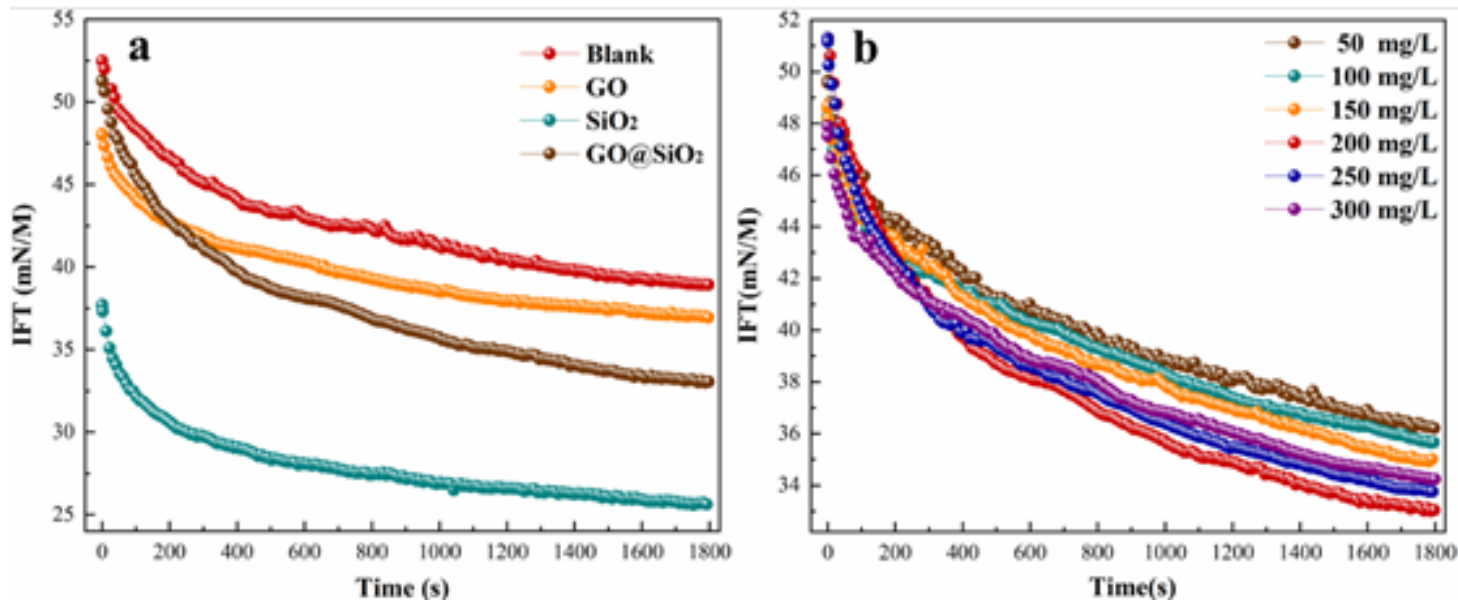

Figure 7

Effect of different samples and GO@SiO2 dosages on IFT. (a) Different samples, (b) different GO@SiO2 dosages 


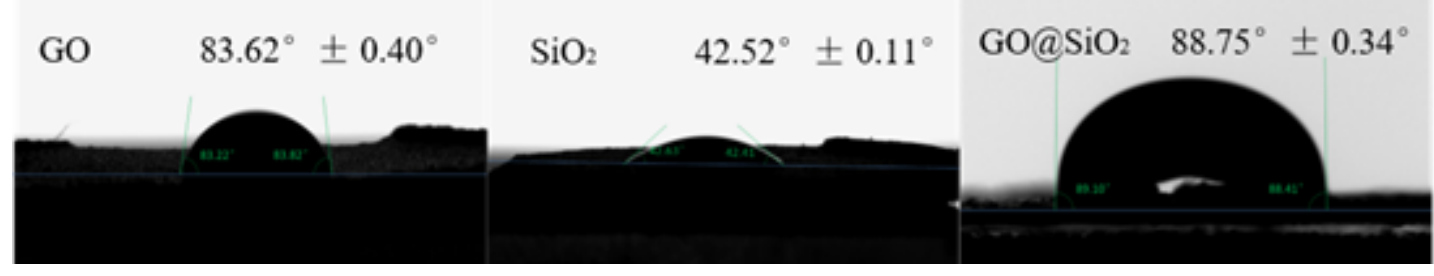

Figure 8

Contact angles of the samples. (a) GO, (b) SiO2 and (c) GO@SiO2

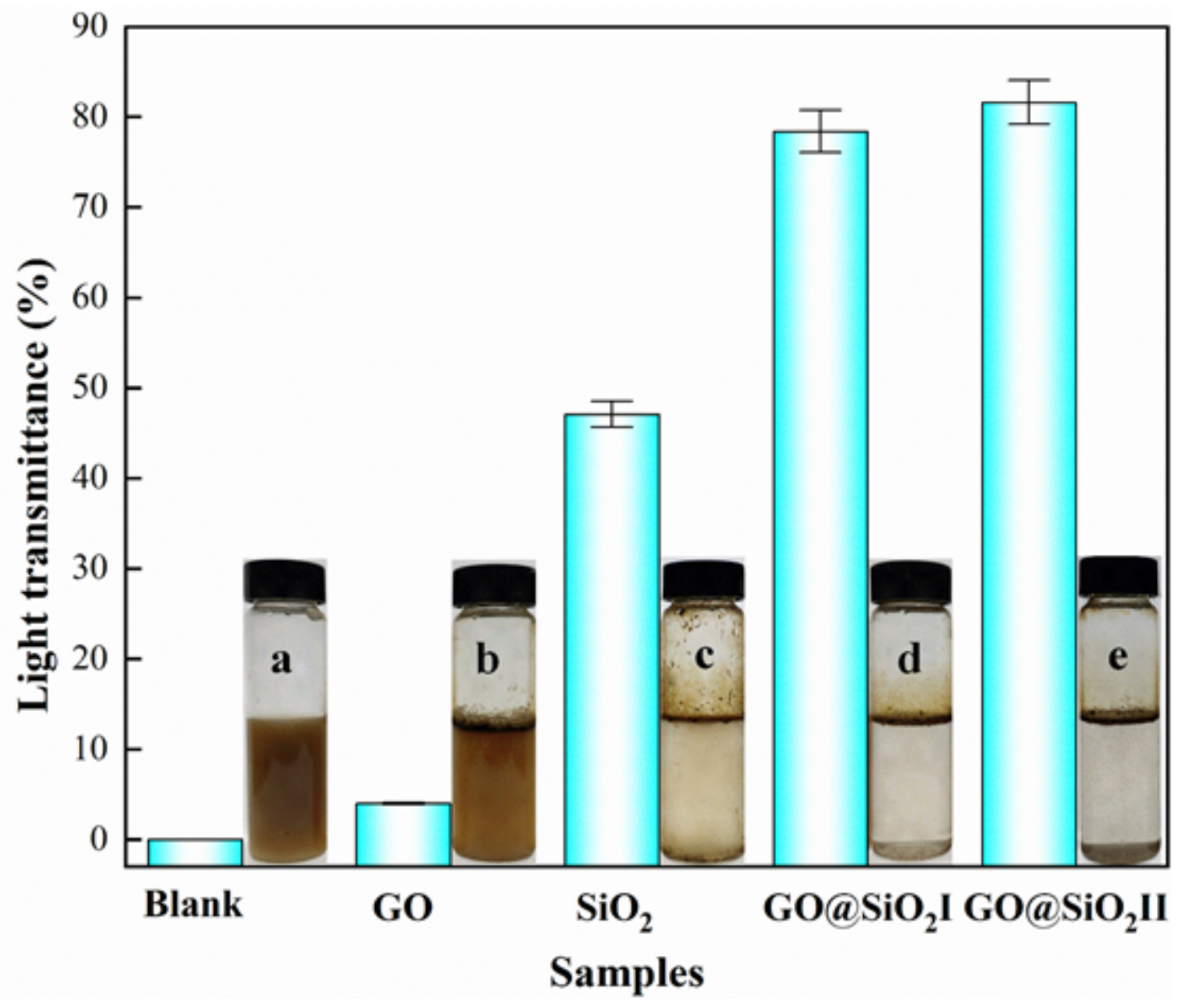

Figure 9

Demulsifying performance of the samples with the dosage of $300 \mathrm{mg} / \mathrm{L}$ in $\mathrm{O} / \mathrm{W}$ emulsion at room temperature for 30min. Inset: Blank (a), GO (b), SiO2 (c), GO@SiO2I (d) GO@SiO2II(e) 


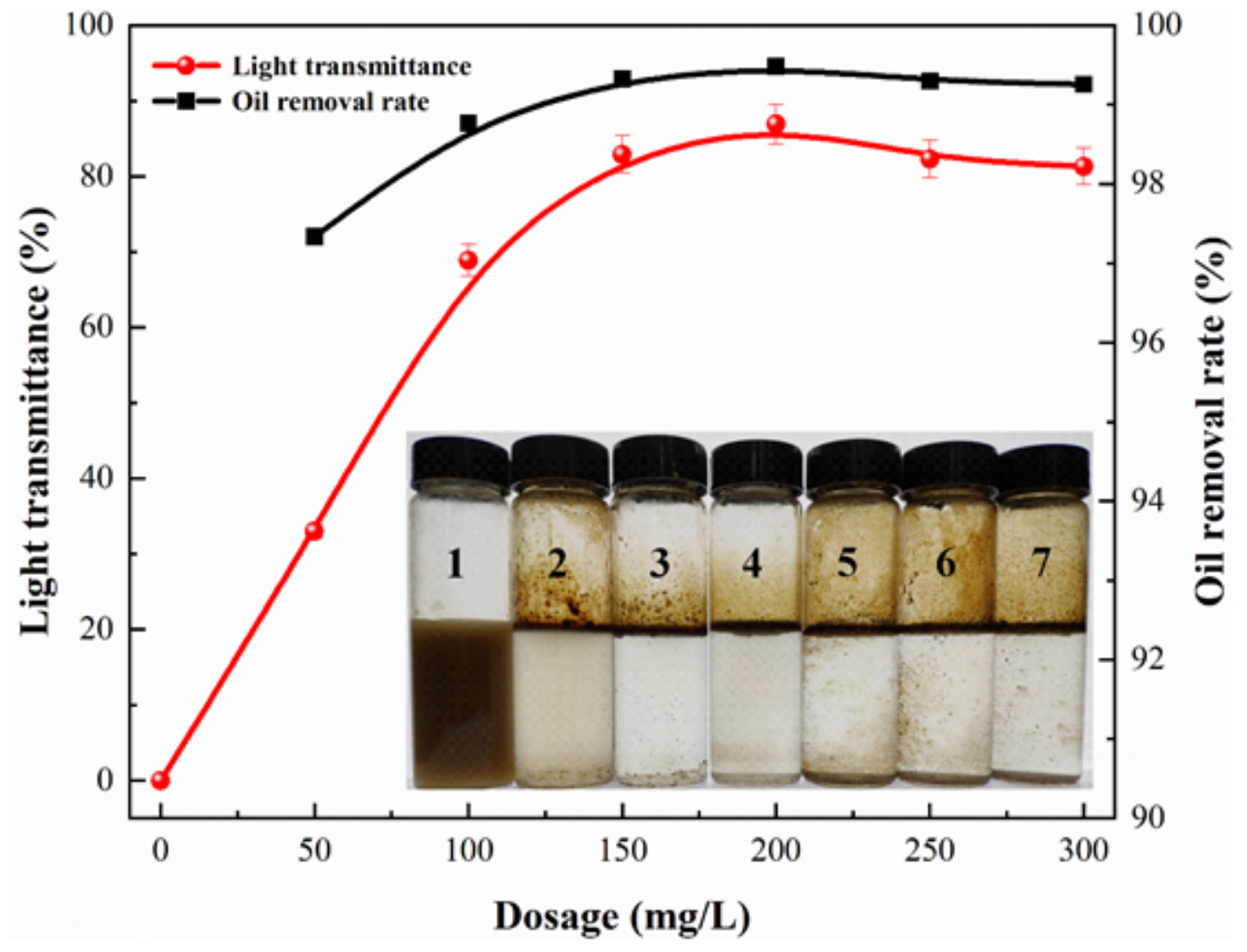

Figure 10

Effect of different dosages of GO@SiO2 on the demulsifying performance at ambient temperature for 30 min. Inset: (1) Blank, (2) 50 mg/L, (3) 100 mg/L, (4) 150 mg/L, (5) 200 mg/L, (6) 250 mg/L, (7) 300 mg/L.

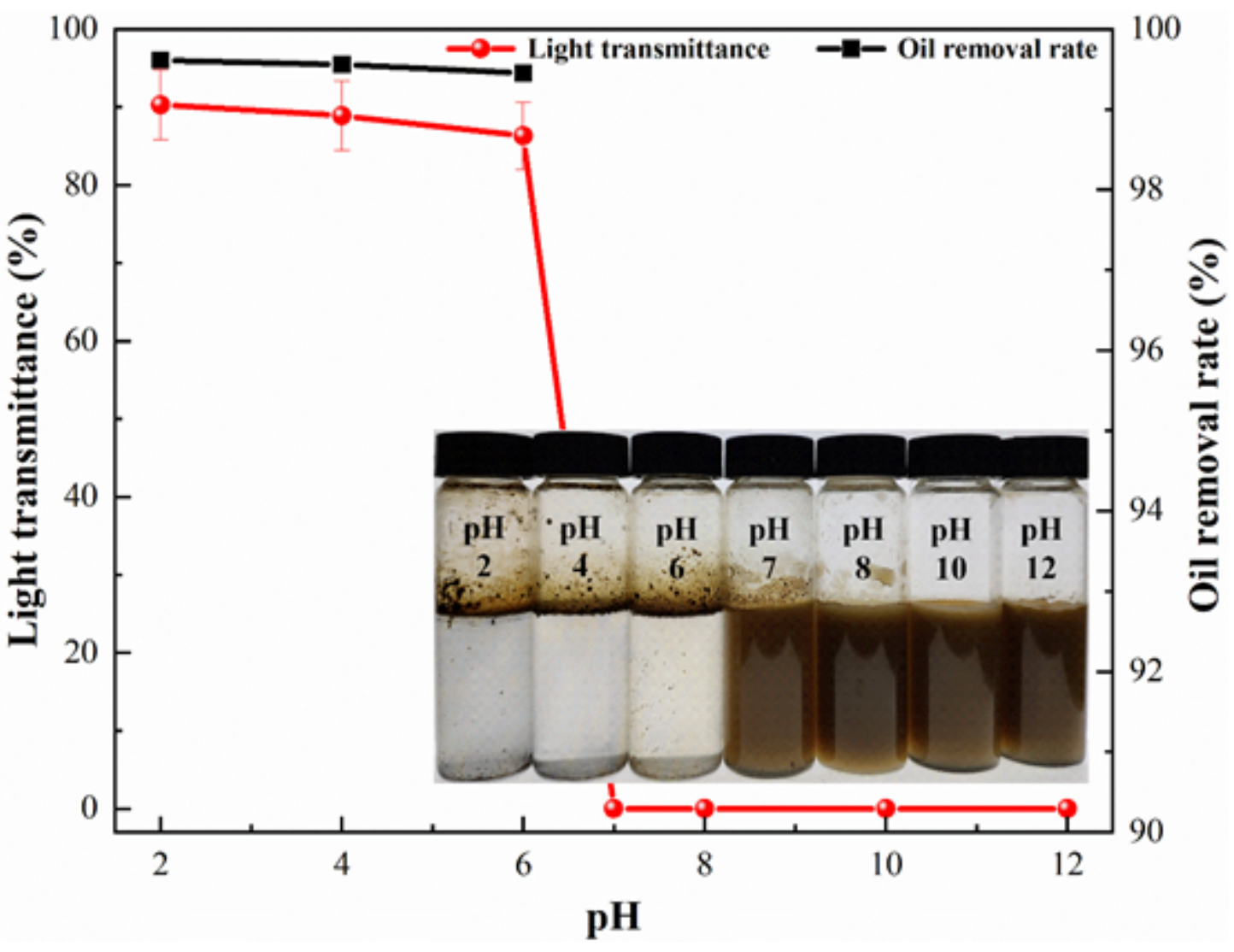


Figure 11

Effect of $\mathrm{pH}$ value on the demulsifying performance with 200mg/L of GO@SiO2 at room temperature for $30 \mathrm{~min}$

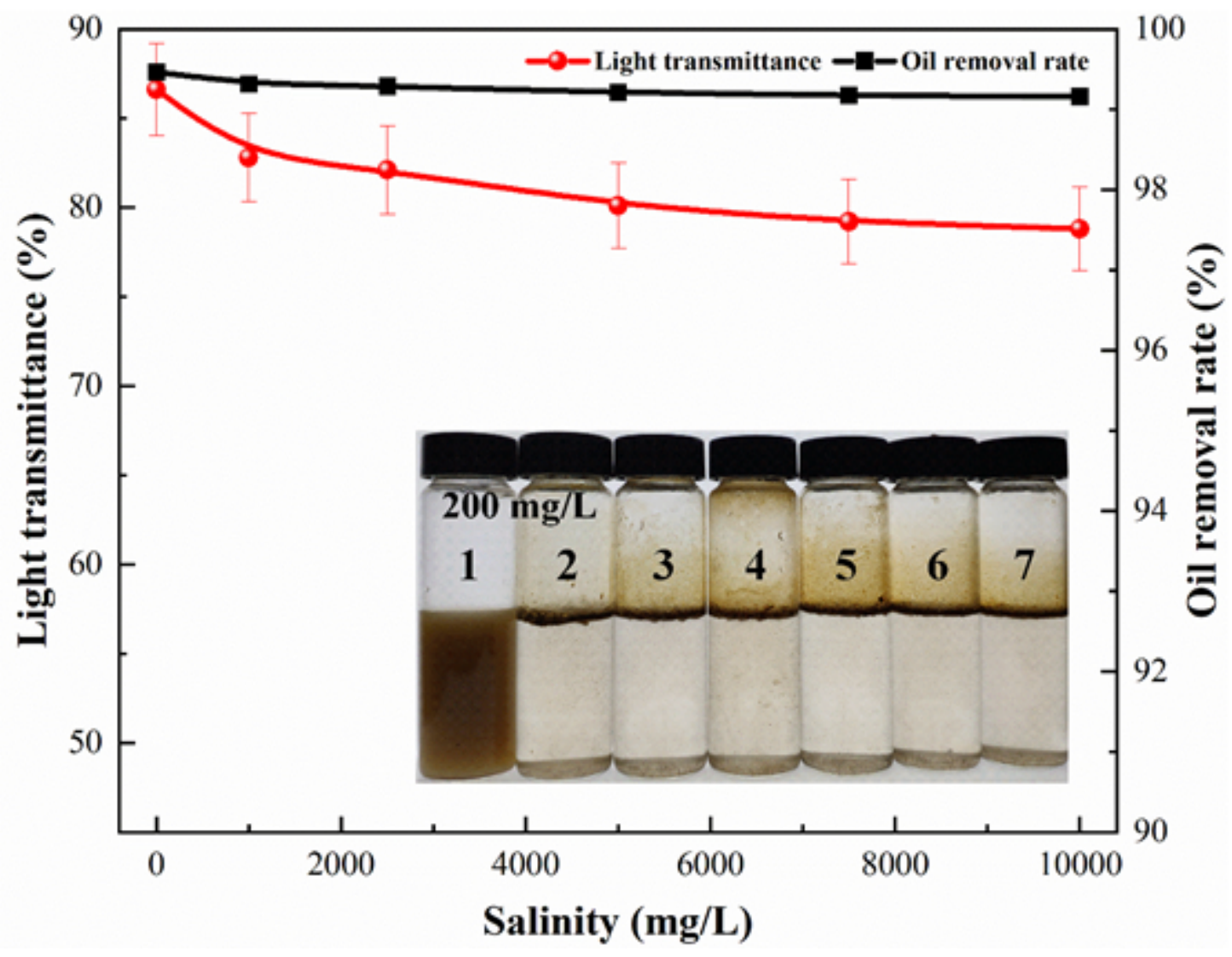

Figure 12

Effect of salinity on the demulsifying performance with 200mg/L of GO@SiO2 at ambient temperature for $30 \mathrm{~min}$. Inset: (1) Blank, (2) 0 mg/L, (3) $1000 \mathrm{mg} / \mathrm{L}$, (4) $2000 \mathrm{mg} / \mathrm{L}$, (5) $5000 \mathrm{mg} / \mathrm{L}$, (6) $7500 \mathrm{mg} / \mathrm{L}$, (7) $10000 \mathrm{mg} / \mathrm{L}$ 


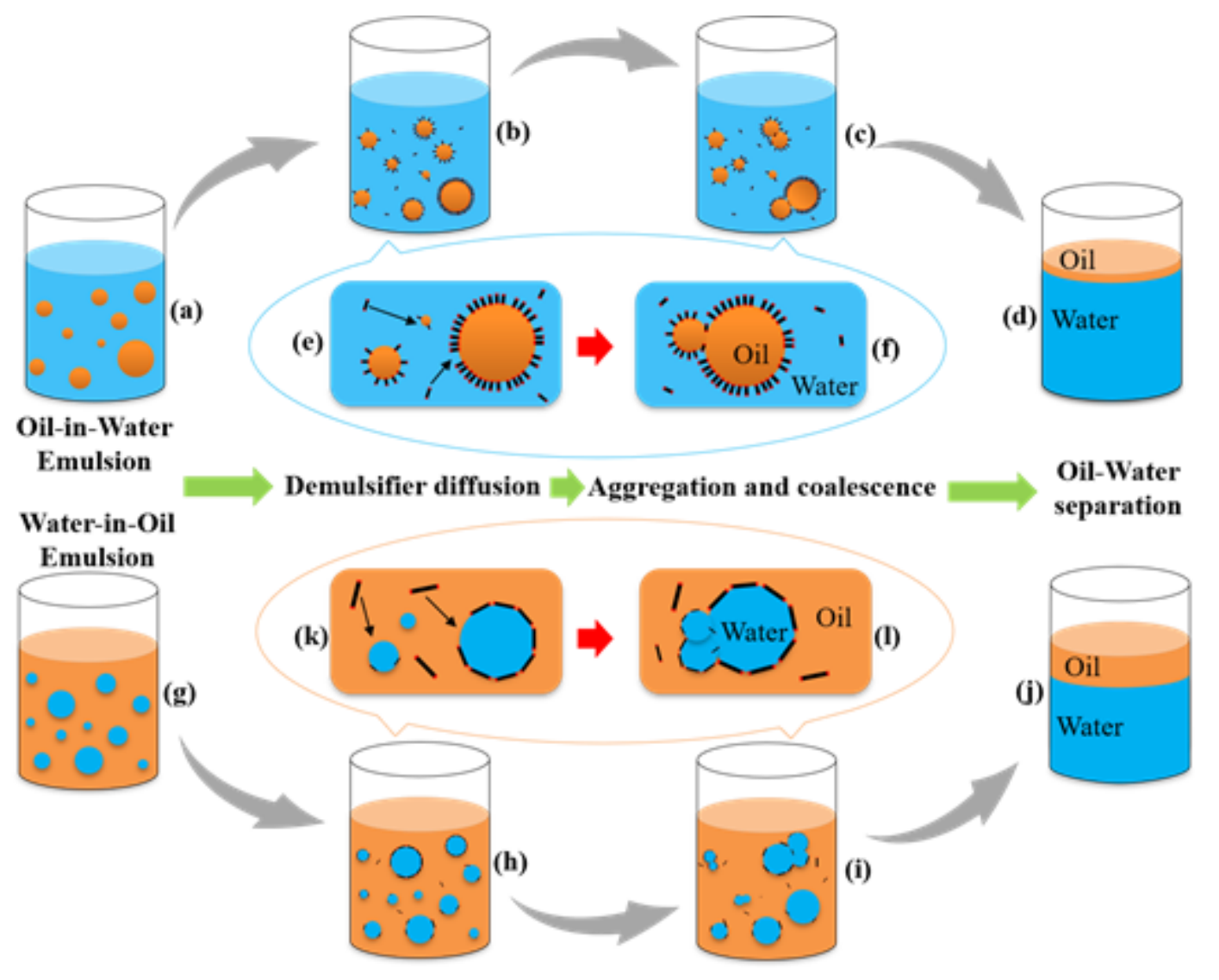

Figure 14

Schematic illustration of the demulsifying mechanism in $\mathrm{O} / \mathrm{W}$ emulsion(a-f) and W/O emulsion(g-l).

\section{Supplementary Files}

This is a list of supplementary files associated with this preprint. Click to download.

- GraphicalAbstract.tif 